\title{
Review
}

\section{Blinding Techniques in Randomized Controlled Trials of Laser Therapy: An Overview and Possible Solution}

\author{
Ian Relf ${ }^{1}$, Roberta Chow ${ }^{2}$ and Marie Pirotta ${ }^{1}$ \\ ${ }^{1}$ Department of General Practice, University of Melbourne, 200 Berkeley Street Carlton 3053, Victoria, and \\ ${ }^{2}$ Private Medical Practice, NSW, Australia
}

\begin{abstract}
Low-level laser therapy has evidence accumulating about its effectiveness in a variety of medical conditions. We reviewed 51 double blind randomized controlled trials (RCTs) of laser treatment. Analysis revealed $58 \%$ of trials showed benefit of laser over placebo. However, less than $5 \%$ of the trials had addressed beam disguise or allocation concealment in the laser machines used. Many of the trials used blinding methods that rely on staff cooperation and are therefore open to interference or bias. This indicates significant deficiencies in laser trial methodology. We report the development and preliminary testing of a novel laser machine that can blind both patient and operator to treatment allocation without staff participation. The new laser machine combines sealed preset and non-bypassable randomization codes, decoy lights and sound, and a conical perspex tip to overcome laser diode glow detection.
\end{abstract}

Keywords: low-level laser therapy-allocation concealment-treatment blinding

\section{Introduction}

Low-level laser therapy in various therapeutic forms is widely used as a medical treatment modality. In general, low-level laser machines deliver laser beams in the $0.1-200 \mathrm{~mW}$ power range from the end of a hand held probe, and only require a small battery/charger/timer unit for normal operation: similar to the modified machine photographed in Figs 1A and B. In Australia, one in five general practitioners use acupuncture in their medical practice, including the use of laser on acupuncture points (1). Laser use has been included alongside needle acupuncture in post-graduate physician training in medical acupuncture for more than 15 years, and is reimbursed as a treatment modality by the Australian Health Insurance Commission.

Laser treatment approaches include: laser on acupuncture points (2), laser therapy for direct treatment of joint

For reprints and all correspondence: Dr Ian Relf, Department of General Practice, University of Melbourne, 200 Berkeley Street Carlton 3053, Victoria, Australia. Tel: 6138344 7276;

E-mail: i.relf@unimelb.edu.au pain (3) and the non-contact laser irradiation technique to facilitate skin and wound healing (4). Although the use of laser on acupuncture points is not yet a proven substitute for needles, it does have demonstrated effectiveness in a limited range of acupuncture responsive conditions (5). A small number of randomized controlled trials (RCTs) have demonstrated significant benefits including treatment of; neck pain, (6-9) low back pain, (10) chronic tension headache, (11) fibromyalgia, (12) enuresis, (5) and post-operative vomiting (2).

The advantages of low-level laser over needles include: ease of application, usage in anatomically dangerous areas, and use in needle-phobic patients including children. It is low cost, non-invasive and safe. (13) General advantages of laser use in RCTs include: (i) Laser light is invisible above $770 \mathrm{~nm}$ and can be switched off or on without visual recognition by the patient or operator. (ii) Low-level laser has been shown to have a negligible sensory stimulus, i.e. patients have difficulty discerning whether they have received real treatment.

The suitability for trial use has been tested in three double blind RCTs: a small trial by Irvine et al. (14) and 

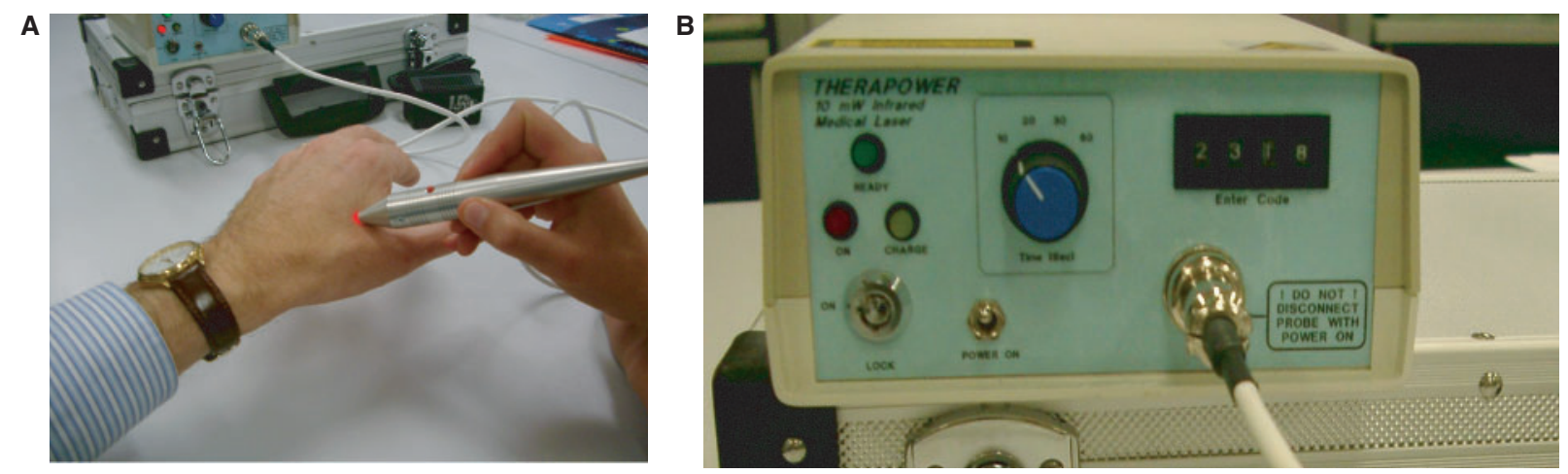

Figure 1. (A) DBL Laser machine in operation for a placebo treatment. Demonstration of laser probe applied to left hand whilst machine is activated. The dummy red light is visible on the skin and is shining out of the end of the probe. The probe is activated by pressing the tiny button visible on the central part of the probe. In this instance, the machine is in full operation, however the invisible infrared laser is switched off as would be the situation for a placebo treatment. The machine activation light on the laser front panel can be seen at the top left of the photograph. Aspect; DBL Laser machine is in the background sitting on carry case. (B) Front panel DBL laser machine. Four-digit patient entry code switch sited in upper right of panel. Indicator lights for machine operation in upper left. Laser probe (white) cord inserted into bottom right panel. Timer switch - central. Manual key lock and power on/off toggle in lower left of panel. Aspect; DBL Laser machine sitting on steel carry case.

two larger trials by Chow $(N=90)(15)$ and Brosseau et al. $(N=88)(16)$ have shown that neither the patient nor operator can discern whether they are using a laser or placebo treatment. Therefore when a laser machine is used correctly it offers a useful way to ensure blinding and treatment allocation where difficulties exist with adequate placebos in needle trials (17).

\section{Research Methods and Laser Trials}

The most important determinants of well-conducted RCTs are adequacy of allocation concealment and blinding procedures. Allocation concealment refers to a process whereby an unbiased allocation sequence is implemented in a secure manner that prevents foreknowledge by either the clinician, researcher or trial participant (18). Generally, allocation concealment appears to be an important indicator of RCT quality, as an analysis of RCTs found that those trials that do not detail an adequate process for allocation concealment show a $40 \%$ increased likelihood of having positive results (19). Therefore, the design of laser machines and processes to ensure allocation concealment and double blinding may be critical to unbiased trial outcomes.

Laser machines delivering visible red light (e.g. using $630 \mathrm{~nm}$ laser diodes) are not suitable for double-blind trials because both the patient and operator can see when the laser is switched on. Even invisible lasers have problems in RCTs as the laser diode itself glows when in use. The diode glow can still be seen in the end of the probe whether or not the resultant beam is visible. This leaves open the possibility that participants could gain foreknowledge of treatment allocation and bias the results. This article reviews the methods of allocation concealment and blinding used in published laser RCTs. We then report the features of a novel laser machine that can blind both patient and operator without the involvement of extra clinical staff, and the results of a small study to test this capacity.

\section{Methods and Results of Literature Review}

A literature review was performed with systematic searches of Medline, Embase, Pubmed, Amed, Cinahl, Ciscom and Cochrane databases. Fifty-one trials of lowlevel laser therapy were found that were double blind clinical RCTs (Tables 1-4).

Analysis of the 51 RCTs showed 30 positive and 21 negative laser trials. However, laser beam detection or machine randomization had only been modified in less than $5 \%$ of these trials. (Table 1) The laser machine described by Toya (6) did address the problem of allocation concealment: a computer was used to turn the laser beam on/off using randomized numbers that were unknown to the operator. This is the only trial using a machine with in-built randomization. The second trial by Krasheninnikoff et al. (20) used a beam filter to preset the laser off or on. However, none of the reviewed trials use a reliable method that addresses the problems of laser diode glow, blinding and allocation concealment in a single laser machine.

The remaining 49 trials (Tables 2-4) used less rigorous methodology for adequate allocation concealment or blinding: 27 trials used identical laser probes or identical laser machines; 17 used on/off switches; eight miscellaneous trials used opaque goggles or other 
Table 1. LLLT trials where laser machine modifications have positive aspects that improve blinding procedures.

\begin{tabular}{|c|c|c|c|c|}
\hline Trial & Condition & Trial result & Positive aspects & Possible methodology problems \\
\hline Krasheninnikoff et al. (20), $N=36$ & Tennis elbow & Negative & Beam filter used & IDLM \\
\hline Toya et al. (6), $N=115$ & Musculoskeletal pain & Positive & External computer controlled & GLO \\
\hline
\end{tabular}

$(N=2)$ Possible methodology problems are: IDLM, Identical laser machine used; GLO, laser diode glow may be visible.

Notes: Total trials $=51$ : references $(6,10,20-22,44,47,49,52)(4,7-9,11,14,23-43,45,46,48,51,53-62)$.

Trials are classified by primary method of blinding.

All trials use invisible laser treatment beam unless otherwise specified.

All laser machines use decoy sound and light as per normal operation.

Three trials: Lundberg, 1987; Haker, 1990; and Haker, 1991- have been removed because of Institutional rulings on scientific practice.

Table 2. LLLT trials that use identical laser machines (IDLM) or identical laser probes (IDLP)

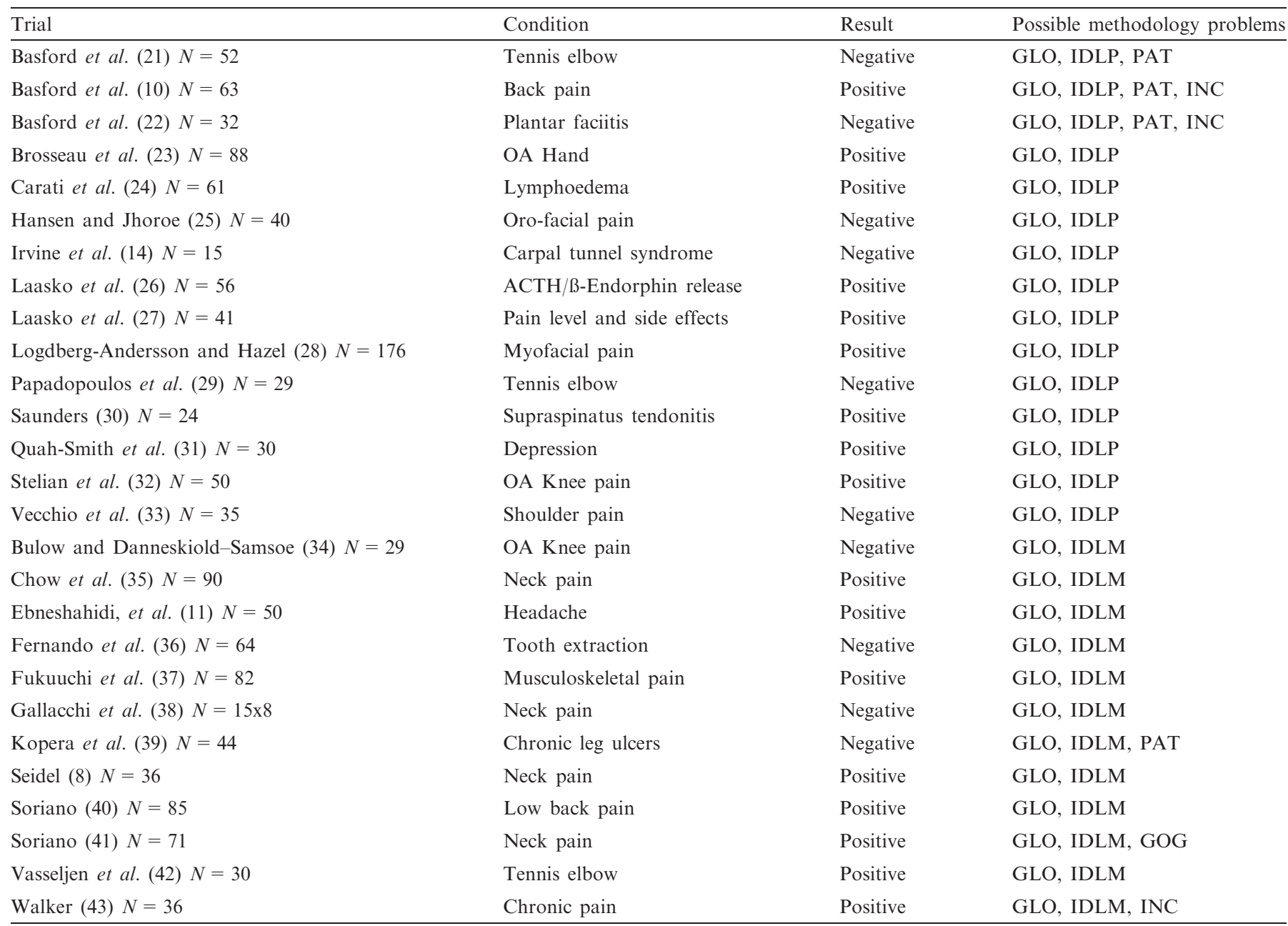

Other possible methodology problems are included. $(N=27)$.

GLO, Laser diode glow may be visible; IDLP, Identical laser probes; IDLM, Identical laser machines; PAT, Patient cooperation is required; GOG, Goggles are used; INC, Incomplete explanation of method.

Notes: Total trials $=51$ : references $(6,10,20-22,44,47,49,52)(4,7-9,11,14,23-43,45,46,48,51,53-62)$.

Trials are classified by primary method of blinding.

All trials use invisible laser treatment beam unless otherwise specified.

All laser machines use decoy sound and light as per normal operation.

Three trials: Lundberg, 1987; Haker, 1990; and Haker, 1991- have been removed because of Institutional rulings on scientific practice.

blinding methods. The explanation of blinding was inadequate in eight trials, nine trials required patient cooperation, and the operator was not blinded in three of the trials. All trials required some degree of staff and/or patient cooperation to conceal treatment allocation and blinding on the day that the patient was being treated, allowing the possibility of bias.

These results demonstrate a need for a laser machine that can properly blind the operator and trial participants, ensuring concealment of treatment allocation. 
Table 3. LLLT trials that use on/off switches (SWI)

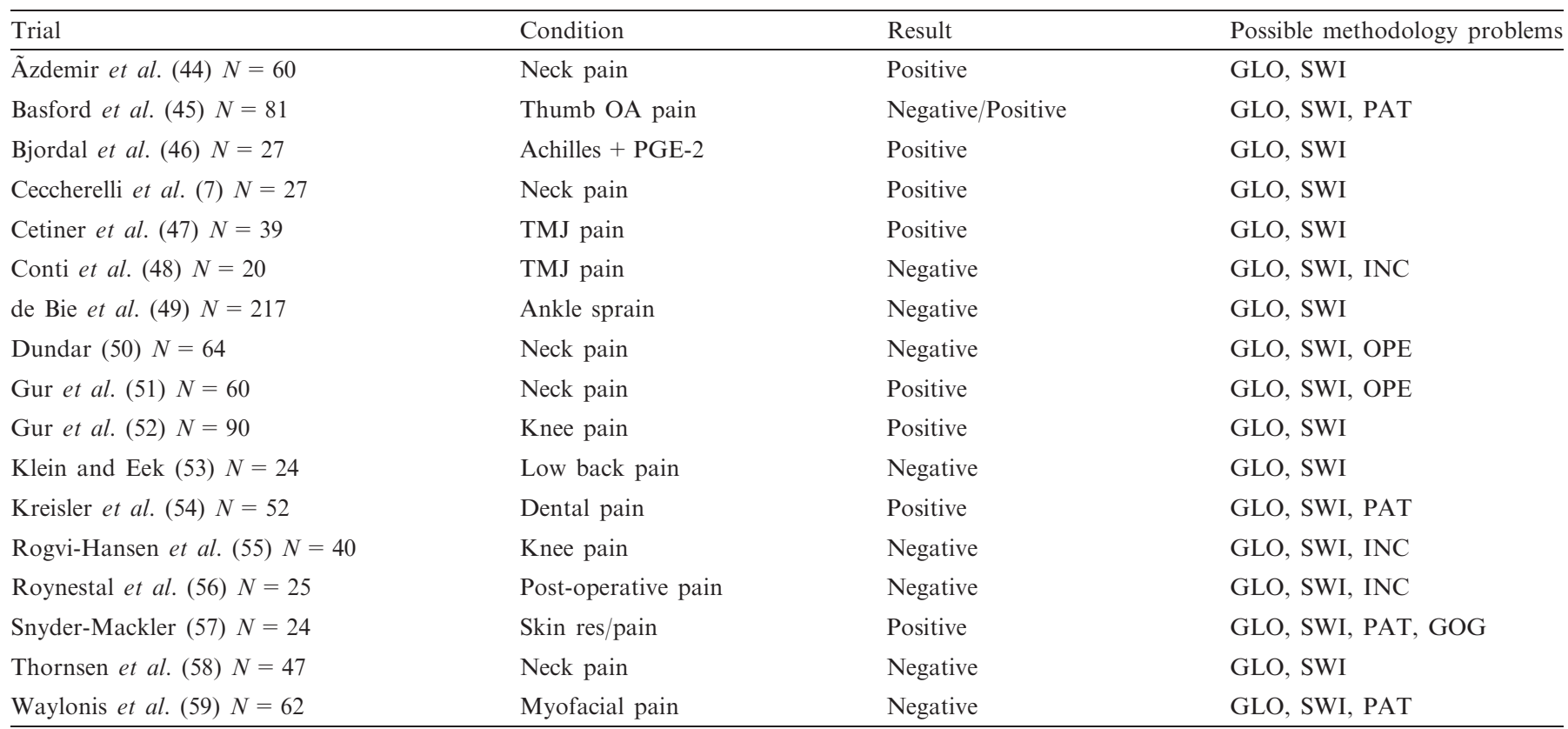

(Other possible methodology problems are included. $(N=17)$.

GLO, Laser diode glow may be visible; SWI, Switch on/off; PAT, Patient cooperation is required; OPE, Operator not blinded; GOG, Goggles are used; INC, Incomplete explanation of method.

Notes: Total trials $=51$ : references $(6,10,20-22,44,47,49,52)(4,7-9,11,14,23-43,45,46,48,51,53-62)$.

Trials are classified by primary method of blinding.

All trials use invisible laser treatment beam unless otherwise specified.

All laser machines use decoy sound and light as per normal operation.

Three trials: Lundberg, 1987; Haker, 1990; and Haker, 1991- have been removed because of Institutional rulings on scientific practice.

Table 4. Miscellaneous LLLT trials $(N=5)$ Other possible methodology problems are included

\begin{tabular}{llll}
\hline Trial & Condition & Result & Possible methodology problems \\
\hline Hopkins et al. (4) $N=22$ & Wound healing & Positive & GLO, OPE, GOG \\
Schindl and Neumann (60) $N=50$ & Recurrent herpes & Positive & GLO, GOG \\
Snyder-Mackler (57) $N=40$ & Nerve latency & Positive & GLO, PAT, OPE \\
Toida et al. (61) $N=20$ & Stomatitis & Positive & GLO, INC \\
Lim et al. (62) $N=39$ & Dental pain & Negative & GLO, INC \\
\hline
\end{tabular}

GLO, Laser diode glow may be visible; PAT, Patient cooperation is required; OPE, Operator not blinded; INC, Incomplete explanation of method; GOG, Goggles are used.

Notes: Total trials $=51$ : references $(6,10,20-22,44,47,49,52)(4,7-9,11,14,23-43,45,46,48,51,53-62)$.

Trials are classified by primary method of blinding.

All trials use invisible laser treatment beam unless otherwise specified.

All laser machines use decoy sound and light as per normal operation.

Three trials: Lundberg, 1987; Haker, 1990; and Haker, 1991- have been removed because of Institutional rulings on scientific practice.

We now describe the features of a recently developed laser machine that combines these aims and report a small study to test these properties.

\section{Novel Laser Machine for RCTs (Figs 1A and $B, 2)$}

A laser machine suitable for use in RCTs should have the following attributes:

- An invisible laser beam.

- Disguised laser diode glow.
- Ability to preset randomized number sets and seal them into the machine.

- Security of internal structures to prevent tampering.

We have developed a new laser machine that is similar in appearance and function to a normal lowlevel laser machine i.e. it has a typically sized hand held laser probe connected to a power source. It also has a timer, sound emitter (beep) and key lock as is normally required by law for laser devices. Added to this are disguises to overcome the ability of operators 


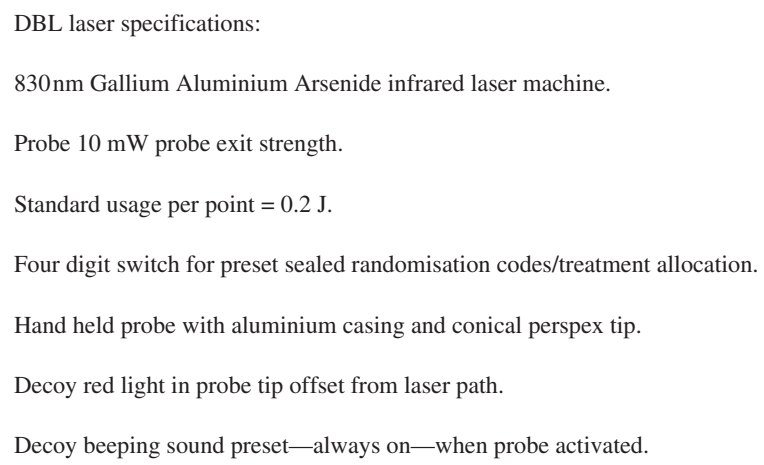

Figure 2. DBL Laser machine specifications.

or patients to see the laser diode glow. These are as follows:

1. A red decoy light: A biologically inactive (63), red, non-coherent non-laser light at $<0.1 \mathrm{~mW}$, is installed beneath the Perspex cone, next to the diode inside the end of the probe. (Fig. 1A) This red light acts as a decoy light and overshadows the small incandescent glow from the diode. This level of red light is below threshold for measurable clinical effects $(45,59)$.

2. Conical perspex cone tip: A conical perspex cone tip has been added to cause partial internal reflection of both the dummy red light and the laser diode glow; thereby 'blending' the two light sources and making direct visual detection of the diode glow impossible. After fitting the conical perspex tip to the laser probe, the laser diode strength has been reset to an exit power of $10 \mathrm{~mW}$ as per the machine's original specification.

3. Allocation concealment is ensured using a randomization keypad: The randomization schedule is generated and held by an independent researcher. This schedule is then built and sealed into each machine at manufacture. This preset schedule number is a code that allocates patients into treatment or placebo groups. Therefore, each participant will be allocated without the knowledge of the participant or treating doctor/operator. Each participant is allocated by entering their particular patient code number into the keypad on the front of the laser machine. (Fig. 1B) As mistakes can occur with the keypad number entry, the patients are asked to check their keypad number with the operator before each treatment.

4. Decoys: When the machine is activated for treatment, it makes an audible beep and the console lights turn on; indicating to the patient that the machine is switched on. These decoys are in operation whether or not the real laser beam is activated. (Fig. 1B)
5. Non-bypass system: the four-digit patient code switch cannot be bypassed. It is impossible for the treatment group allocation to be altered after being preset and sealed in manufacture.

6. Equipment testing: the preset randomization schedule can be checked by an independent researcher prior to the commencement of the trial.

\section{Method of Laser Machine Testing}

To test our novel machine in its capacity to ensure allocation concealment and blinding, a sample of 20 doctors was asked to participate in a double blind test. The group was an opportunistic sample of doctors who practiced medical acupuncture and presented for a discussion group on medical acupuncture treatment in chronic pain. All of them were familiar with the usage and risks of low-power lasers and consented to participate. There were no refusals. They knew there were deliberate disguises in place i.e. the decoy red light and perspex cone. Participants were asked to examine the laser machine and activate the laser whilst switched between two-unknown preset positions that switched the real laser beam off and on. The participants were asked to determine whether they could see the laser diode operating through the perspex cone. The possible responses: either 'on', 'off' or 'cannot tell', were recorded.

\section{Results and Discussion of Laser Machine Testing}

In this preliminary study, none of the 20 laser familiar participants could see the operation of the laser diode. This is supportive evidence that the laser diode disguise is effective and overcomes this important problem in double blinding laser trials. The preset concealed randomizationcoding system also worked effectively.

\section{Conclusions}

Analysis of 51 double blind RCTs of laser treatment revealed $58 \%$ showed benefit of laser over placebo. However, less than $5 \%$ of the trials had addressed beam disguise or allocation concealment in the laser machines used. This indicates significant deficiencies in laser trial methodology. A new laser machine has been developed that can blind both patient and operator to treatment allocation without staff participation. Preliminary testing has verified that the laser machine diode operation could not be detected, and the preset sealed randomizationcoding system was effective. We consider this machine could be a useful tool in conducting double blind RCTs, however a larger clinical study should be undertaken before it can be fully validated as a trial instrument. 


\section{Acknowledgments}

We would like to thank Dr Alan Harvey who built the DBL Trial Laser machine with assistance from the Royal Melbourne Institute of Technology and Acupak Pty. Ltd. Melbourne, Australia.

\section{References}

1. Pirotta MV, Cohen MM, Kotsirilos V, Farish SJ. Complementary therapies: have they become accepted in general practice? Med $J$ Aust 2000;172:105-9.

2. Schlager A, Offer T, Baldissera I. Laser stimulation of acupuncture point P6 reduces postoperative vomiting in children undergoing strabismus surgery. Br J Anaesth 1998;81:529-32.

3. Bjordal JM, Couppe C, Chow RT, Tuner J, Ljunggren EA. A systematic review of low level laser therapy with location-specific doses for pain from chronic joint disorders. Aust $J$ Physiother 2003;49:107-16.

4. Hopkins JT MT, Seegmiller JG, Baxter GD. Low-level laser therapy facilitates superficial wound healing in triple blind, sham-controlled study. J Athl Train 2004;39:223-9.

5. Radmayr C, Schlager A, Studen M, Bartsch G. Prospective randomized trial using laser acupuncture versus desmopressin in the treatment of nocturnal enuresis. Eur Urol 2001:40:201-05.

6. Toya SMM, Inomata K, Oshiro T, Macda T. Report on Computerrandomized double blind trial to determine the effectiveness of GaAIAs (830NM) Diode laser for pain attenuation in selected pain groups. Laser Ther 1994;6:143-8.

7. Ceccherelli F, Altafini L, Lo Castro G, Avila A, Ambrosio F, Giron GP. Diode laser in cervical myofascial pain: a double-blind study versus placebo. Clin J Pain 1989;5:301-04.

8. Seidel UC. A randomised controlled double blind trial comparing dose laser therapy on acupuncture points and acupuncture for chronic cervical syndrome. Deutsche Zeitschrift fur Akupunkture 2002;45:258-69.

9. Chow RT, Heller GZ, Barnsley L. The effect of $300 \mathrm{~mW}, 830 \mathrm{~nm}$ laser on chronic neck pain: A double-blind, randomized, placebocontrolled study. Pain 2006;124:201-10.

10. Basford JR, Sheffield CG, Harmsen WS. Laser therapy: a randomized, controlled trial of the effects of low-intensity Nd:YAG laser irradiation on musculoskeletal back pain. Arch Phys Med Rehabil 1999;80:647-52.

11. Ebneshahidi NS, Heshmatipour M, Moghaddami A, EghtesadiAraghi P. The effects of laser acupuncture on chronic tension headache-a randomised controlled trial. Acupunct Med 2005;23:13-18.

12. Gur A, Karakoc M, Nas K, Sevik R, Sarac J, Demir E. Efficacy of low power laser therapy in fibromyalgia: a single-blind, placebocontrolled trial. Lasers Med Sci 2002;17:57-61.

13. Wong TW, Fung KP. Acupuncture: from needle to laser. Fam Pract 1991;8:168-70.

14. Irvine J, Chong SL, Amirjani N, Chan KM. Double-blind randomized controlled trial of low-level laser therapy in carpal tunnel syndrome. Muscle Nerve 2004;30:182-7.

15. Chow R. Sensory detection of $830 \mathrm{Nm}$ laser by patients in double blind trial of chronic neck pain. PhD Thesis, University of Sydney, Australia; 2005

16. Brosseau GW, Marchand S, Gaboury I, Stokes B, Morin M, Casimiro L, et al. Randomized controlled trial on low level laser therapy (LLLT) in the treatment of osteoarthritis (OA) of the hand. Lasers in Surg Med 2005;36:210-19.

17. Goddard G, Karibe H, McNeill C, Villafuerte E. Acupuncture and sham acupuncture reduce muscle pain in myofascial pain patients. J Orofac Pain 2002;16:71-6.

18. Schulz K, Chalmers I, Altman D. The landscape and lexicon of blinding in randomized trials. Ann Intern Med 2002;136:254-9.

19. Schulz KF, Chalmers I, Hayes RJ, Altman DG. Empirical evidence of bias. Dimensions of methodological quality associated with estimates of treatment effects in controlled trials. JAMA 1995;273:408-12.
20. Krasheninnikoff M, Ellitsgaard N, Rogvi-Hansen B, Zeuthen A, Harder K, Larsen R, et al. No effect of low power laser in lateral epicondylitis. Scand J Rheumatol 1994;23:260-3.

21. Basford JR, Sheffield CG, Cieslak KR. Laser therapy: a randomized, controlled trial of the effects of low intensity Nd:YAG laser irradiation on lateral epicondylitis. Arch Phys Med Rehabil 2000;81:1504-10.

22. Basford JR, Malanga GA, Krause DA, Harmsen WS. A randomized controlled evaluation of low-intensity laser therapy: plantar fasciitis. Arch Phys Med Rehabil 1998;79:249-54.

23. Brosseau L, Gam A, Harman K, Morin M, Robinson VA, Shea BJ, et al. Low Level Laser Therapy (Classes I, II and III) for Treating Osteoarthritis. Oxford: The Cochrane Library, 2005.

24. Carati CJ, Anderson SN, Gannon BJ, Piller NB. Treatment of postmastectomy lymphedema with low-level laser therapy: a double blind, placebo-controlled trial. Cancer 2003;98:1114-22.

25. Hansen HJ, Thoroe U. Low power laser biostimulation of chronic oro-facial pain. A double-blind placebo controlled cross-over study in 40 patients. Pain 1990:43:169-79.

26. Laakso EL CT, Richardson C, Galligan JP. Plasma ACTH and Beta-endorphin levels in response to low level laser therapy (LLLT) for myofascial trigger points. Laser Ther 1994;6:133-42.

27. Laakso EL RC, Cramond T. Pain scores and side effects in response to low level laser therapy (LLLT) for myofacial trigger points. Laser Ther 1997;9:67-72.

28. Logdberg-Andersson MS, Hazel A. LLLT of tendinitis and myofacial pains- a randomised, double blind controlled study. Laser Ther 1997;9:79-86.

29. Papadopoulos ES, Cawley MID, Mani R. Low-level laser therapy does not aid the management of tennis elbow. Clin Rehabil 1996;19:9-11.

30. Saunders L. The efficacy of low-level laser therapy in supraspinatus tendinitis. Clin Rehabil 1995;9:126-34.

31. Quah-Smith JI, Tang WM, Russell J. Laser acupuncture for mild to moderate depression in a primary care setting-a randomised controlled trial. Acupunct Med 2005;23:103-11.

32. Stelian J, Gil I, Habot B, Rosenthal M, Abramovici I, Kutok N, et al. Improvement of pain and disability in elderly patients with degenerative osteoarthritis of the knee treated with narrow-band light therapy. J Am Geriatr Soc 1992;40:23-6.

33. Vecchio P, Cave M, King V, Adebajo AO, Smith M, Hazleman BL. A double-blind study of the effectiveness of low level laser treatment of rotator cuff tendinitis. Br J Rheumatol 1993;32:740-2.

34. Bulow PM, Danneskiold-Samsoe JH. Low power Ga-Al-As laser treatment of painful osteoarthritis of the knee. A double blind placebo-controlled study. Scand J Rehabil Med 1994:26:155-9.

35. Chow RT, Barnsley L, Heller GZ, Siddall PJ. Efficacy of $300 \mathrm{~mW}$, $830 \mathrm{~nm}$ laser in the treatment of chronic neck pain: a survey in a general practice setting. J Musculoskelet Pain 2003;11:13-21.

36. Fernando S, Hill CM, Walker R. A randomised double blind comparative study of low level laser therapy following surgical extraction of lower third molar teeth. Br J Oral Maxillofac Surg 1993;31:170-2.

37. Fukuuchi ASH, Inoue K. A double blind trial of low reactive-level laser therapy in the treatment of chronic pain. Laser Ther 1998;10:59-64.

38. Gallacchi GMW. Acupuncture and treatment with laser radiation in cases of cervical and lumbar syndromes. $J$ Phys Med 1981;2:95-102.

39. Kopera D, Kokol R, Berger C, Haas J. Low level laser: does it influence wound healing in venous leg ulcers? A randomized, placebo-controlled, double-blind study. $\mathrm{Br} \quad J$ Dermatol 2005;152:1368-70.

40. Soriano FRR. Gallium arsenide laser treatment of chronic low back pain: a prospective randomized and double blind study. Laser Ther 1998;10:175-80.

41. Soriano FRR, Pedrola M, Giagnorio J, Battagliotti CR. Acute cervical pain is relieved with gallium arsenide laser radiation. A double blind preliminary study. Laser Ther 1996;8:149-54.

42. Vasseljen O Jr, Hoeg N, Kjeldstad B, Johnsson A, Larsen S. Low level laser versus placebo in the treatment of tennis elbow. Scand $J$ Rehabil Med 1992;24:37-42. 
43. Walker J. Relief from chronic pain by low power laser irradiation. Neurosci Lett 1983;43:339-44.

44. Âzdemir F, Birtane M, Kokino S. The clinical efficacy of low-power laser therapy on pain and function in cervical osteoarthritis. Clin Rheum 2001:20:181-4.

45. Basford JR, Sheffield CG, Mair SD, Ilstrup DM. Low-energy helium neon laser treatment of thumb osteoarthritis. Arch Phys Med Rehabil 1987;68:794-7.

46. Bjordal JM, Lopes-Martins RAB, Iversen VV, Chow R. A randomised, placebo controlled trial of low level laser therapy for activated Achilles tendinitis with microdialysis measurement of peritendinous prostaglandin E2 concentrations. $\mathrm{Br} J$ Sports Med 2006;40:76-80.

47. Cetiner S, Kahraman SA, Yucetas S. Evaluation of low-level laser therapy in the treatment of temporomandibular disorders. Photomed Laser Surg 2006;24:637-41.

48. Conti PC. Low level laser therapy in the treatment of temporomandibular disorders (TMD): a double-blind pilot study. Cranio 1997;15:144-9.

49. de Bie RA, de Vet HCW, Lenssen TF, van den Wildenberg FAJM, Kootstra G, Knipschild PG. Low-level laser therapy in ankle sprains: a randomized clinical trial. Arch Phys Med Rehabil 1998;79:1415-20.

50. Dundar U, Evcik D, Samli F, Pusak H, Kavuncu V. The effect of gallium arsenide aluminium laser therapy in the management of cervical myofacial pain syndrome: a double blind, placebocontrolled study. Clin Rheumatol 2007;26:930-4.

51. Gur A SA, Cevik R, Altindag O, Sarac S. Efficacy of $904 \mathrm{~nm}$ gallium arsenide low level laser therapy in the management of chronic myofascial pain in the neck: a double-blind and randomized controlled trial. Lasers Surg Med 2004:35:229-35.

52. Gur AC, Sarac AJ, Cevik R, Nas K, Uyar A. Efficacy of different therapy regimes of low-power laser in painful osteoarthritis of the knee: a double-blind and randomized-controlled trial. Lasers Surg Med 2003;33:330-8.

53. Klein RG, Eek BC. Low-energy laser treatment and exercise for chronic low back pain: double-blind controlled trial. Arch Phys Med Rehabil 1990;71:34-7.
54. Kreisler MB, Al Haj H, Noroozi N, Willershausen B, D'hoedt B. Efficacy of low level laser therapy in reducing postoperative pain after endodontic surgery: a randomized double blind clinical study. Int $J$ Oral Maxillofac Surg 2004:33:38-41.

55. Rogvi-Hansen B, Ellitsgaard N, Funch M, Dall-Jensen M, Prieske J. Low level laser treatment of chondromalacia patellae. Int Orthop 1991;15:359-61.

56. Roynesdal AK, Bjornland T, Barkvoll P, Haanaes HR. The effect of soft-laser application on postoperative pain and swelling: a double-blind, crossover study. Int Jf Oral Maxillofacl Surgery 1993;22:242-5.

57. Snyder-Mackler L. Effect of helium-neon laser irradiation on peripheral sensory nerve latency. Phys Ther 1988;68:223-5.

58. Thorsen H, Gam AN, Svensson BH, Jess M, Jensen MK, Piculell I, et al. Low level laser therapy for myofascial pain in the neck and shoulder girdle. A double-blind, cross-over study. Scand $J$ Rheumatol 1992;21:139-41.

59. Waylonis GW, Wilke S, O'Toole D, Waylonis DA, Waylonis DB. Chronic myofascial pain: management by lowoutput helium-neon laser therapy. Arch Phys Med Rehabil 1988;69:1017-20.

60. Schindl A, Neumann R. Low-intensity laser therapy is an effective treatment for recurrent herpes simplex infection. Results from a randomized double-blind placebo-controlled study. $J$ Invest Dermatol 1999;113:221-3.

61. Toida M, Watanabe F, Goto K, Shibata T. Usefulness of low-level laser for control of painful stomatitis in patients with hand-foot-and-mouth disease. $J$ Clin Laser Med Surg 2003;21:363-7.

62. Lim HM, Lew KK, Tay DKL. A clinical investigation of the efficacy of low level laser therapy in reducing orthodontic postadjustment pain. Am J Orthod Dentofacial Orthop 1995;108:614-22.

63. Flemming LA, Cullum NA, Nelson EA. A systematic review of laser therapy for venous leg ulcers. $J$ Wound Care 1999;8:111-14.

Received April 1, 2006; accepted March 9, 2007 


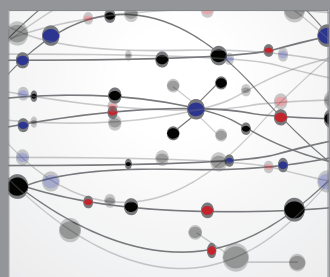

The Scientific World Journal
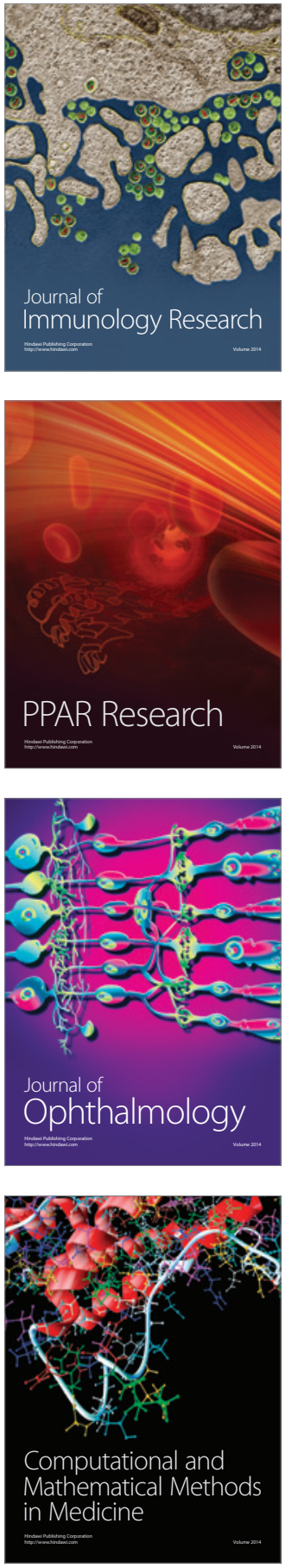

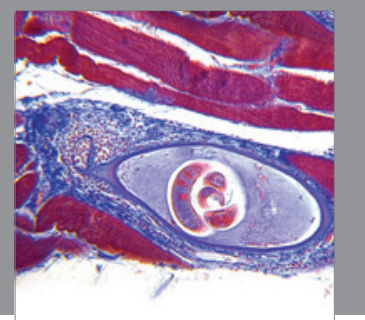

Gastroenterology

Research and Practice
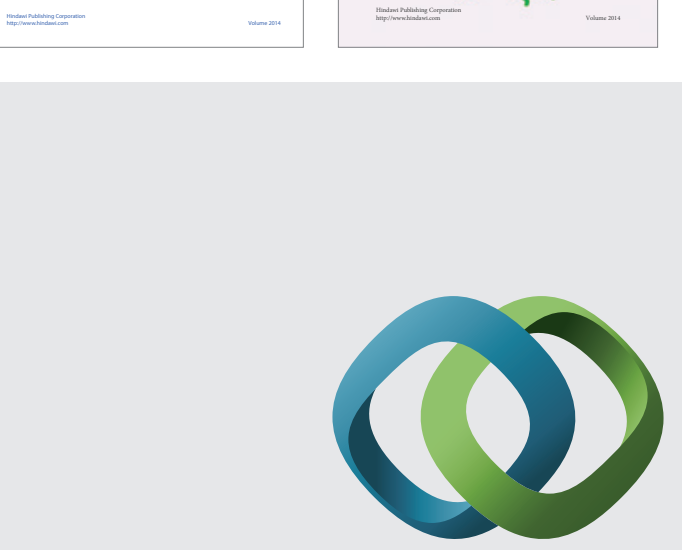

\section{Hindawi}

Submit your manuscripts at

http://www.hindawi.com
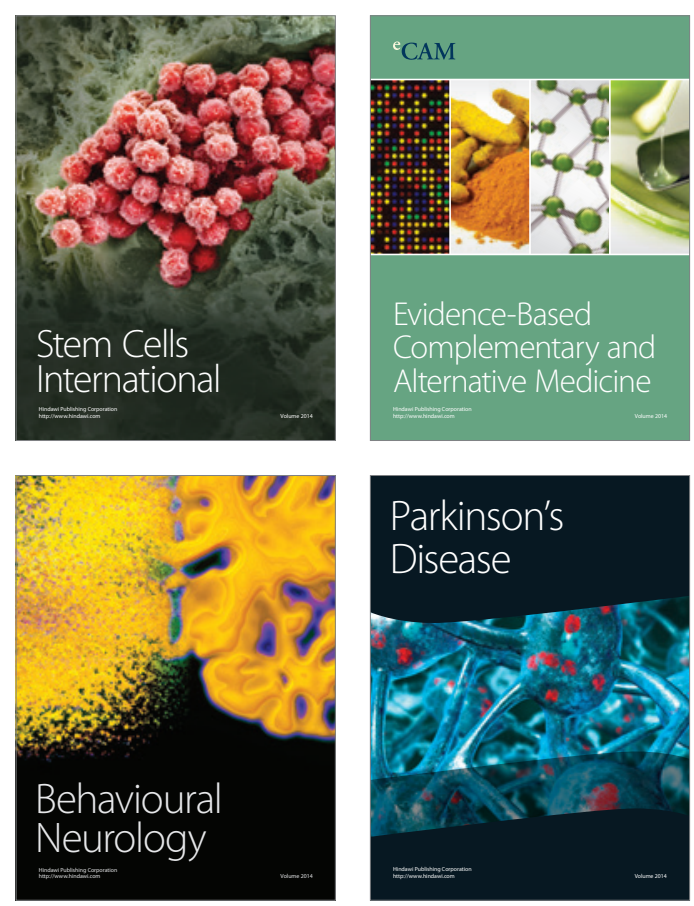

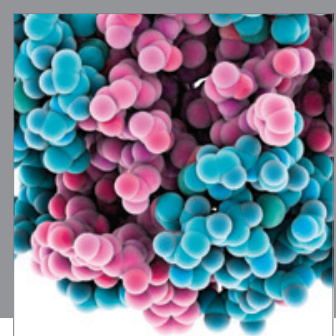

Journal of
Diabetes Research

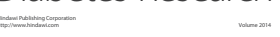

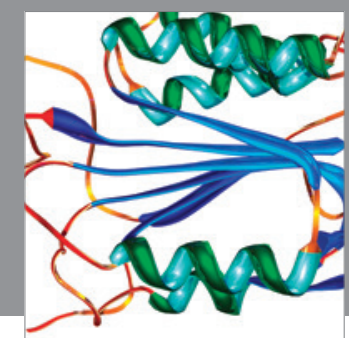

Disease Markers
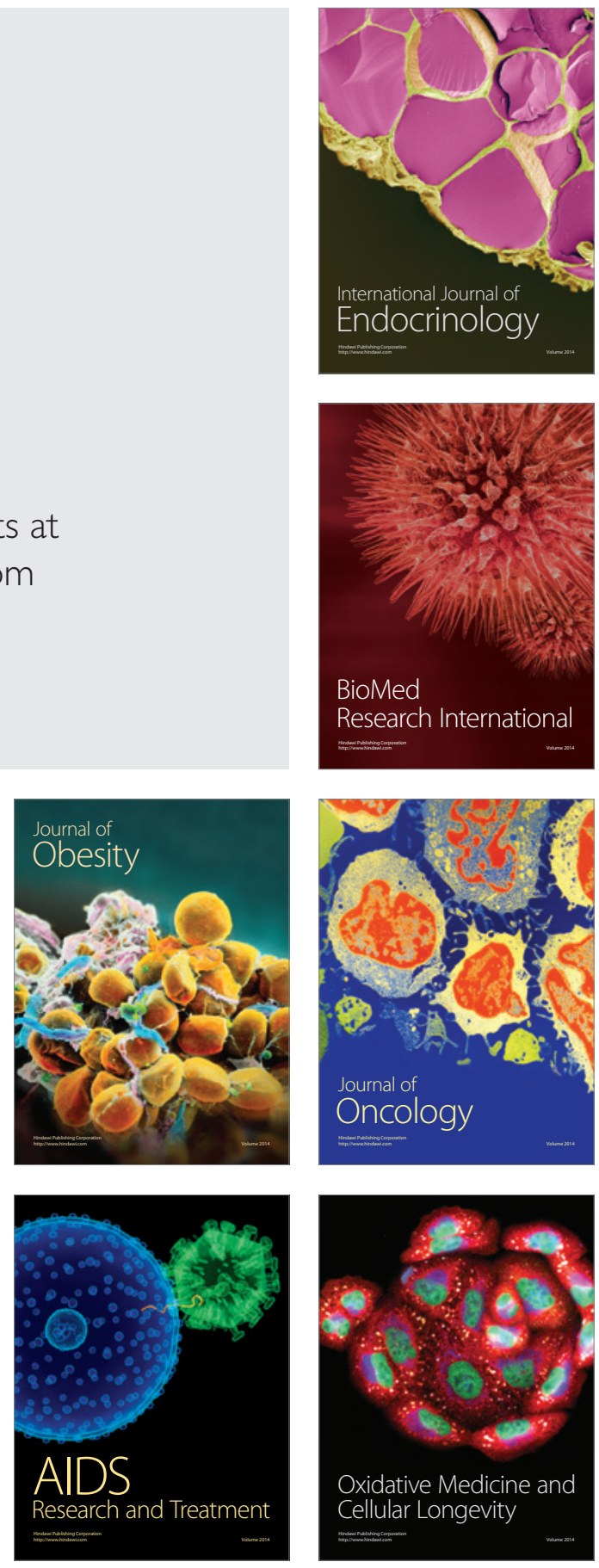